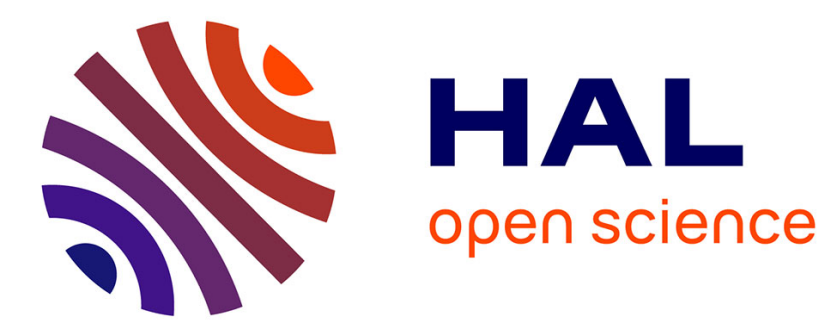

\title{
Who pays the costs of non-GMO segregation and identity preservation?
}

\author{
Marion Desquilbet, D.S. Bullock
}

\section{To cite this version:}

Marion Desquilbet, D.S. Bullock. Who pays the costs of non-GMO segregation and identity preservation?. IATRC 2001: General membership meeting, Dec 2001, Tucson, United States. 35 p. hal02283458

\section{HAL Id: hal-02283458 \\ https://hal.science/hal-02283458}

Submitted on 7 Jun 2020

HAL is a multi-disciplinary open access archive for the deposit and dissemination of scientific research documents, whether they are published or not. The documents may come from teaching and research institutions in France or abroad, or from public or private research centers.
L'archive ouverte pluridisciplinaire HAL, est destinée au dépôt et à la diffusion de documents scientifiques de niveau recherche, publiés ou non, émanant des établissements d'enseignement et de recherche français ou étrangers, des laboratoires publics ou privés.

\section{(이) $\$$}

Distributed under a Creative Commons Attribution - NonCommercial - NoDerivatives| 4.0 


\title{
Who pays the costs of non-GMO segregation and
}

\section{identity preservation?}

\author{
Marion Desquilbet \\ Institut National de la Recherche Agronomique \\ Economie et Sociologie Rurales, Rennes, France \\ David S. Bullock
}

University of Illinois, Department of Agricultural and Consumer Economics

Paper presented at the International Agricultural Trade Research Consortium, 2001 General Membership Meeting, Tucson, Arizona, December 14-16, 2001

Corresponding author: Marion Desquilbet, INRA ESR, 4 allée Adolphe Bobierre, CS 61103, 35011 Rennes cedex, France. Phone: (33) 2234856 08. Fax: (33) 2234853 80. desquilb@roazhon.inra.fr. Co-author: David S. Bullock, Department of Agricultural and Consumer Economics, University of Illinois, 305 Mumford Hall, 1301 W. Gregory Drive, Urbana, IL 61801. Phone: (217) 333-5510. Fax: (217) 333-5538. dsbulloc@uiuc.edu. Copyright 2001 by Desquilbet and Bullock. All rights reserved. Readers may make verbatim copies of this document for non-commercial purposes by any means, provided that this copyright notice appears on all such copies. 


\title{
Who pays the costs of non-GMO segregation and identity preservation?
}

\begin{abstract}
This paper proposes an analytical framework to examine the market and welfare impacts of GMOs, when some consumers refuse genetically modified organisms (GMOs) and when two supply channels are segregated (one for goods that containing GMOs and one for non-genetically-modified identity-preserved goods). Our analytical framework begins at the level of individual farmers, handlers and consumers, to build up market supply and demand functions. This allows us to circumvent the difficulties of conducting supply and demand analysis in the different horizontally and vertically related markets concerned by GMOs and market segregation. We represent explicitly the costs of non-GMO segregation and identity preservation (IP) for both producers of non-GM IP goods and producers of non-IP goods, and how these costs vary depending on the relative sizes of the two production channels. We then illustrate our model by a simulation of potential adoption of GM rapeseed with non-GMO market segregation in the European Union (EU). We analyze how the costs of IP are distributed among heterogenous producers, handlers and consumers in this simulation.
\end{abstract}




\section{Who pays the costs of non-GMO segregation and identity preservation? ${ }^{1}$}

\section{Introduction}

Some major world agricultural markets are currently facing a dual situation with regard to genetically modified organisms (GMOs), with many farmers growing GMOs and many consumers reluctant to eat them, or many national regulations slow to accept their use. As a result, some seed producers, farmers, grain handlers and food processors are striving to preserve the identity of non genetically modified goods by keeping them segregated from genetically modified (GM) goods, to meet demand for non-GM goods. A dual stream of supply and marketing is developing, one for goods without GMOs above given tolerance levels, and one for goods that contain GMOs above these tolerance levels. This paper proposes an analytical supply and demand framework to examine the economic effects of this non-GMO segregation and identity preservation (IP). The original features of our model are that we begin at the level of individual agents to build up market supply and demand functions, and that we represent explicitly the costs of non-GMO segregation and IP for both producers of non-GM IP goods and producers of non-IP goods. We then conduct a simulation of potential adoption of GM rapeseed with non-GMO IP in the European Union (EU), and we analyze how the costs of IP are distributed among different agents.

\section{The literature}

So far, studies on the economic effects of GMO labeling and non-GMO segregation and IP have mainly examined how to account for differentiated

\footnotetext{
${ }^{1}$ We thank Hervé Guyomard and Vincent Réquillart, INRA ESR, France, for helpful comments on previous versions of this paper. Remaining errors are our own.
} 
consumers' attitudes towards GMOs in an analytical framework, and what are the effects of market segregation on consumers. However, less attention has been given to the way to model costs of segregation and IP and how these costs affect producers.

Mayer and Furtan (1999) analyze graphically the effects of market segregation between GM and non-GM products on the Canadian rapeseed (canola) market. They consider two different demand curves for GM canola and for non-GM canola, and two interdependent supply curves, one for GM canola and one for non-GM canola, with the two goods being substitutes in supply, so that two distinct prices arise in equilibrium for GM and non-GM canola. They do not model explicitly how the costs of segregation of GM and non-GM products are shared between producers, but they suggest three possibilities: the costs are borne by all canola production, by only transgenic production, and by only non-GM production.

Nielsen, Thierfelder and Robinson (2001) introduce different GM and non-GM production technologies and different preferences towards GM and non-GM products in a CGE framework and illustrate the effects of different representations of preference changes. Their paper is mainly aimed at showing how to model differentiated preferences towards GM and non-GM products in the CGE framework. They do not introduce costs of segregation, and their only constraint for non-GM processed products is that they are produced using a non-GM bulk ingredient.

Without adopting a formal modeling framework, Golan and Kuchler (2001) consider the change from an initial equilibrium with only non-biotech food to a final equilibrium with both biotech food and identity-preserved non-biotech food. They argue that when GMOs are introduced, externality costs are imposed on producers of the non-GM good to ensure that its non-GM identity is preserved until its final consumption. According to their analysis, these externality costs are only borne by 
non-GM producers. Then, compared to the initial equilibrium, in their final equilibrium, consumers who are indifferent between GMOs and non-GMOs pay a lower price, due to GMO costs savings, while consumers who prefer non-GMOs pay a higher price, due to $\mathbb{P}$ costs.

Giannakas and Fulton (2001) examine the effects of GMOs and GMO labeling on consumer demand and consumer welfare, using a model of differentiated consumer preferences on GM and non-GM products. They analyze how the effects of introduction of GMOs and of GMO labeling depend on the degree to which GM cost savings are passed to consumers, on the level of consumer aversion to GMOs, on the segregation costs associated with mandatory labeling, and on the extent of mislabeling. They argue that while both non-GM and GM producers may face some segregation costs, these costs will always be higher for producers of the IP good than for producers of the GM good, due to the effort required in preserving the identity of the non-GM good by keeping it separate from the GM good.

\section{Sources of the costs of segregation and identity preservation}

The studies reviewed above account for differential characteristics among consumers, and notably point out that GMOs and non-GMO segregation can cause some consumers to win while others lose. However, they give less attention to the way segregation and $\mathrm{P}$ costs are borne. Moreover, they make different, and sometimes even contradictory a priori assumptions about these IP costs. In this context, our aim is to analyze more closely how these IP costs arise, which producers bear these costs, how farmers and handlers are differentiated with respect to these costs, and if the effects of GMOs and non-GMO segregation and IP on their welfare are also variable. 
It is possible to distinguish two main categories of costs of non-GMO segregation and IP (Bullock and Desquilbet, 2001). The first category is costs to prevent commingling of GMOs and non-GMOs, i.e. to keep non-GMOs intended to IP physically separated from GMOs along the supply chain. In particular, costs are incurred to prevent cross-pollination, to clean farm, handling, transportation and processing equipment, and to dedicate one part of this equipment to GMOs while dedicating the other to non-GMOs. The second category is of costs to correct the information asymmetry about the GMO or non-GMO nature of the goods, i.e. to ensure the buyer that grain that is claimed as non-GM by the seller is actually nonGM. These costs are from chemical testing and drawing up contracts between buyers and sellers and monitoring their abidance. These additional costs have three important characteristics. First, they are likely to arise for both producers of non-GM IP goods (which we will call simply "IP goods") and producers of goods for which no steps are taken to prevent GMO commingling (which we will call "regular goods"). Second, these additional costs are likely to be different from one agent to the other. Third, these costs are likely to depend on the types of goods, i.e., IP or regular goods, produced by other agents in the economy. These three characteristics of IP costs are illustrated below, using partly the example of the current IP channel in the United States (US) and in the EU.

\section{Farm costs of segregation and IP}

In the case of farmers, it is possible to cite three $\mathbb{P}$ costs that vary among farmers, that depend on the size of the IP channel or that arise for both producers of the regular good or producers of the IP good. The first is the cost of transporting IP grain to an elevator willing to accept it. Currently in the US, IP crops make up a small share of total supply, and only a fraction of all elevators are participating in the IP 
channel. Moreover, some of these elevators are only receiving IP crops from farmers during specified periods, and not near harvest time. In this situation, the additional cost of delivering $\mathbb{P}$ grain to an accepting elevator varies among farmers. The additional cost is small for a farmer located near an elevator accepting IP grain at harvest time, or for a farmer possessing adequate on-farm storage and located near an elevator accepting IP grain only out of harvest time. On the contrary, the additional cost is likely to be dissuasive for a farmer located far away from an elevator accepting IP grain, or for a farmer possessing inadequate on-farm storage capacity, even though he may be located near an elevator accepting $\mathrm{IP}$ grain only out of harvest time. In addition, for a given farmer, the cost of delivering $\mathbb{P}$ grain to an elevator accepting it depends on the size of the IP channel. If the share of IP crops in total supply increases, some new elevators will start to accept IP crops, or will accept them during wider periods of time. Then, the cost of participating in an IP channel will decrease for some farmers located near these elevators. Yet simultaneously, as the size of the $\mathbb{P}$ channel grows, a similar cost of participating in the regular channel will arise for producers of the regular good. In the extreme situation where the size of the regular channel is very small, the cost of transporting regular grain to an elevator willing to accept it could become dissuasive for many farmers.

The second type of farm IP cost that varies among farmers is the cost of preventing cross-pollination by GM plants. For cross-pollinated species (including corn and rapeseed, but excluding soybeans which are almost exclusively selfpollinated), pollen from neighboring GM fields can fertilize plants in a non-GM field and lead to the commingling of GM and non-GM seed or grain. To prevent cross pollination, it is necessary to adopt costly measures such as increasing distance between one's non-GM fields and GM fields, or harvesting border rows separately. 
Here again, this cost varies among farms (for example, depending on the presence of natural barriers or depending on wind direction). It also varies for a given farmer depending on the share of GM crops in total supply (this cost increases for some farmers as the share of GM crops in total supply increases, when some of their neighbors begin to grow GM crops). (Here, no similar cost exists for producers of the regular good, because regular producers do not have to prevent cross-pollination of their crops by non-GM pollen).

The third type of farm IP cost that varies among farmers is the opportunity cost borne from not using GM technology in production. Several studies underline that economic benefits from adopting GMOs vary widely between farmers (Bullock and Nitsi, 2001; McBride and Books, 2000; Desquilbet, Lemarié and Levert, 2001). One main reason is that different farmers face different weed situations, or different insect pressures, so that pesticide cost reductions or yield changes following from GMO adoption vary among them. Then, the potential indirect cost of not using a GM seed in order to grow an IP crop varies among farmers.

\section{Handling and processing costs of segregation and IP}

At the handling stage, too, some examples show that IP costs vary among handlers and vary depending on the size of the IP channel in total supply. In the current situation where the IP channel is small in the USA, because of the physical design of their facilities, some elevators have smaller costs than others of participating in the IP channel. For example, strict tolerance levels can be attained more easily in storage locations that have multiple paths (as opposed to a single path) of dump pits, legs, conveyors belts, etc, along which grain is moved before being stored. It is also easier to segregate $\mathrm{P}$ crops in a facility with multiple small storage bins rather than few large bins. Moreover, having different elevators in close proximity is an 
advantage for some handlers that may dedicate some elevator locations to GMOs and others to non-GMOs. This situation will change if the share of IP crops in the handling system increases and new elevators enter the IP channel. In the EU, where only IP crops are supplied, all facilities are used exclusively for IP crops. In this case, this physical design and location of elevators does not create IP cost differences among handlers. Similarly, regular crops may also bear a cost of segregation. For while regular crops need not be kept clean of non-GM crops, segregation still can lead to costs of capacity underuse, cleaning costs, and management costs to organize more complicated grain flows. Similar cost differences and variations of cost with the size of the IP channel apply to food processors.

\section{Analytical framework}

In order to analyze the aspects of non-GMO segregation and IP described above, we develop a model allowing welfare analysis of GMOs and IP using supply and demand analysis. To conduct an applied analysis, a typical procedure would be to assume functional forms for the supply and demand functions of the pertinent markets, then to calibrate the model's supply and demand parameters. This calibration step would require either to estimate these parameters using historical price and quantity data or to define their value a priori. Our description of IP costs suggests that the aggregate quantities of each type of good supplied by farmers, handlers and processors depend on the prices of regular and IP goods at the different stages and on the relative sizes of the regular and IP channels. Aggregate final demands for both types of goods are expected to depend on the prices of regular and IP goods at the consumer stage. It would be a challenge to calibrate market supply and demand 
function parameters in a multi-market, vertically-connected sector, since very little data exists to suggest what the pertinent supply and demand parameters might be.

The alternative formulation that we suggest here is to start from supply and demand at the individual level, and to define aggregate supply and demand functions by summing up individual supplies and demands. The advantage of this formulation is to avoid a priori assumptions on functional forms at the aggregate level. Rather than defining elasticities of supply with respect to prices of each good and with respect to the relative sizes of the two channels, quantity changes as a reaction to price and relative size changes are then derived implicitly from assumptions on parameters at the individual level, which are easier to calibrate a priori. Another interesting feature results from this formulation at the individual level. Since the model consists in modeling heterogeneous individual agents, it allows to distinguish how GMOs and non-GMO segregation affect the heterogenous members of the same interest groups.

Our model is of two vertically related markets, a market of agricultural products at the farm stage and a market of agricultural products at the handling stage, and two countries, a domestic country (the EU), and the rest of the world (ROW). We consider four different goods that may be produced by farmers. The first good (indexed by $n$ ) is rapeseed grown from a non-GM seed, but for which no steps are taken to prevent possible commingling with GM rapeseed, or which is not delivered to handlers accepting IP crops. The second good (indexed by $g$ ) is rapeseed from a GM seed. The third good (indexed by $i$ ) is non-GM IP rapeseed (later referred to simply as "IP"), grown from a non-GM seed, for which special efforts are made to avoid any commingling with GM rapeseed. The fourth good (indexed by $a$ ) is an alternative crop. Handlers buy rapeseed from farmers, to produce either regular handled rapeseed (indexed by $r$ ), or $\mathbb{P}$ handled rapeseed (indexed by $i$ ). We assume that $\mathrm{P}$ handled 
rapeseed can only be produced using IP farm rapeseed. Regular handled rapeseed is rapeseed that cannot be sold as IP and is produced using GM rapeseed or non-GM non-IP rapeseed (handlers view these as the same product). For simplicity, we make the partial equilibrium assumption that farm crop $a$ has a constant price and we do not consider any cross-effects between handling of rapeseed and handling of the alternative good. Consumers buy regular rapeseed and IP rapeseed from handlers, they buy a close substitute to rapeseed in consumption, and they buy a numeraire good.

This model allows us to take into account three simultaneous shifts in supply and/or demand curves in three different markets. First, the GMO technology lowers costs of production for some subset of all farmers. Second, for many consumers, worry about possible health and environmental effects of GMOs causes their demand for GM versus non-GM products to shift in favor of non-GM products. This shift in preferences begets a third shift, this time in the demand for segregation and identity preservation of non-GMOs.

\section{Domestic farmers}

We consider a set of $F$ farmers, each of whom may produce the four different farm crops $n, g, i$ or $a$. Each of the four crops is produced using land, owned by each farmer in equal area $L$, and a set of variable inputs. Each of the four goods is produced under competitive conditions using a Leontief technology, with the variable inputs perfectly elastic in supply and land perfectly inelastic in supply. Handlers do not distinguish between the two types of regular rapeseed, i.e., non-GM non-IP rapeseed and GM rapeseed. Therefore, farmers are paid the same price for these two products. There is a production externality for regular and IP rapeseed producers. As a result, 
the costs of production of regular rapeseed depend on the share of $\mathrm{P}$ rapeseed in total handled rapeseed. In the same way, the costs of production of IP rapeseed depend on the share of regular rapeseed in total handled rapeseed. ${ }^{2}$ Farmers get the same constant yield $y$ for each of the three types of rapeseed. Let $w_{r}$ denote the farm price of regular rapeseed (i.e., rapeseed $n$ or rapeseed $g$ ), let $w_{i}$ denote the farm price of IP rapeseed (i.e., rapeseed $i$ ), let $v$ denote the vector of variable input prices, and let $s$ denote a government per-hectare subsidy on rapeseed. We denote the per hectare crop-specific restricted profit on crop $k$ by farmer $f$ as $\pi^{k f}(),. k=n, g, i$. The cropspecific per-hectare profit function for crop $n$ is given by: ${ }^{3}$

(1) $\pi^{n f}\left(w_{r}, v, \tau_{i}, s\right)=\operatorname{Max}\left(w_{r} y+s-c_{n f}(v)-e_{r f}(v) \tau_{i} ; 0\right)$

where $c_{n f}(v)$ is farmer $f$ 's per-hectare variable cost of production for crop $n$ when regular rapeseed is the only good supplied; $e_{r f}(v)$ is a production externality parameter for regular rapeseed; $\tau_{i}$ is the share of $\mathbb{P}$ rapeseed to total rapeseed (i.e. to IP plus regular rapeseed) in the handling system.

${ }^{2}$ Some causes of these externality costs were presented in section 2: costs to bring regular or IP rapeseed to an elevator accepting it; cost to prevent GM cross-pollination of IP rapeseed. By nature, these costs depend on where other regular and IP farmers and elevators are located. We take them into account in a simple way in our non-spatial framework, by assuming that they depend only on the share of the other good (IP or regular) in total aggregate handled quantities.

${ }^{3}$ It can be shown that the profit function given in (1) is derived from a Leontief production function of the type : $Y_{n f}=\operatorname{Min}\left\{\frac{\alpha_{f}}{\tau_{i}} x_{0 n}, \beta_{1 f} x_{1 n}, \beta_{2 f} x_{2 n}, \ldots, \beta_{m f} x_{m n}, \gamma L_{n}\right\}$, where, we have $\alpha_{f}, \beta_{i f}$ (for $j \in\{1, \ldots, m\}$ ), and $\gamma$ are parameters describing the technology when farmer $f$ grows crop $n$, $x_{0 n}, \ldots, x_{m n}$ are quantities of variable inputs $0, \ldots, m$ the farmer devotes to crop $n$, and $L_{n}$ is the amount of land the farmer devotes to crop $n$. Input 0 is needed only when $\tau_{i}$ is strictly positive, and the larger is $\tau_{l}$, the higher is the quantity of input 0 necessary to produce the amount $Y_{n f}$. Let $v=\left(v_{0}, \ldots, v_{m}\right)$ denote the vector of prices of inputs $0, \ldots, m$. Then it can be shown that yield $y$ is equal to $\gamma$, $c_{n f}(v)=\sum_{j=1}^{m} \frac{\nu_{j} y}{\beta_{m f}}$ and $e_{r f}(v) \tau_{i}=\frac{\nu_{0} y}{\alpha_{f}} \tau_{i}$. 
The crop-specific profit functions for crops $g$ and $i$ are defined in an analogous manner as:

(2) $\pi^{g f}\left(w_{r}, v, \tau_{i}, s\right)=\operatorname{Max}\left(w_{r} y+s-c_{g f}(v)-e_{r f}(v) \tau_{i} ; 0\right)$

(3) $\pi^{i f}\left(w_{i}, v, \tau_{r}, s\right)=\operatorname{Max}\left(w_{i} y+s-c_{i f}(v)-e_{i f}(v) \tau_{r}, 0\right)$

where $e_{i f}(v)$ is a production externality parameter for IP rapeseed; $\tau_{r}$ is the share of regular rapeseed to total rapeseed in the handling system, equal to $1-\tau_{i}$.

The profit level obtained from the alternative crop is constant and equal to $\pi^{a}$ for each farmer. The technology specified (see footnote 1) implies that for each crop the farmer has constant returns to scale. Therefore the farmer will never devide his land among different crops, but will always find it optimal to grow only one crop, the one yielding the maximum profit level (provided that this profit level is positive). Farmer $f$ 's maximum per-hectare profit is given by (suppressing arguments $v$ and $s$ ):

(4) $\pi^{\max f}\left(w_{r}, w_{i}, \tau_{i}\right)=\operatorname{Max}\left(\pi^{n f}\left(w_{r}, \tau_{i}\right) ; \pi^{g f}\left(w_{r}, \tau_{i}\right) ; \pi^{i f}\left(w_{i}, 1-\tau_{i}\right) ; \pi^{a}\right)$

Depending on prices, some farmers may then find it optimal in equilibrium to grow GM rapeseed, while others find non-GM seed more profitable, some with and some without identity-preserving their crop. Farmer $f$ s supply function for crop $k=n$, $g, i$ is then defined by: ${ }^{4}$

(5) $q_{k}^{s f}\left(w_{r}, w_{i}, \tau_{i}\right)=\left\{\begin{array}{c}y L \text { if } \pi^{\max f}(.)=\pi^{k f}(.) \\ 0 \text { otherwise }\end{array}\right.$.

The aggregate farm supply function of crop $k=n, g, i$ is denoted $q_{k}^{s A F}($.$) , and is$ defined as the sum of individual supplies for that crop:

\footnotetext{
${ }^{4}$ Equation (4) assumes that the profit-maximizing crop is unique. In the case where more than one crop-specific profit levels is equal to the maximum profit level, we arbitrarily decide that the farmer grows only one of the profit-maximizing crops, with crop $n$ being the most preferred, then $\mathrm{g}$, then $i$, then $a$.
} 
(6) $q_{k}^{s A F}\left(w_{r}, w_{i}, \tau_{i}\right)=\sum_{f=1}^{F} q_{k}^{s f}\left(w_{r}, w_{i}, \tau_{i}\right)$

\section{Domestic handlers}

We consider a set of $H$ handlers indexed by $h=1, \ldots, H$ who may produce the two different types of handled rapeseed, $r$ or $i$. Handled rapeseed is produced with a Leontief technology, combining farm rapeseed, storage capacity and variable inputs, with one unit of farm rapeseed necessary to produce one unit of handled rapeseed. Regular handled rapeseed is produced using rapeseed $n$ or $g$, and the amount of regular rapeseed bought from farmers by handler $h$ is by definition $q_{r h}=q_{n h}+q_{g h}$. IP handled rapeseed is produced using farm I rapeseed $i$. Storage capacity is owned by each handler in a given quantity $Q$ and is perfectly inelastic in supply, and variable inputs are perfectly elastic in supply. There is a production externality for regular and IP rapeseed producers. As a result, the costs of production of regular rapeseed depend on the share of IP rapeseed in total handled rapeseed. In the same way, the costs of production of IP rapeseed depend on the share of regular rapeseed in total rapeseed. ${ }^{5}$ We denote the per hectare crop-specific restricted profit of handler $h$ on crop $k$ as $\pi^{k h}(),. k=r, i$. The crop-specific per-unit-of-capacity profit function for crop $r$ is given by:

(7) $\pi^{r h}\left(p_{r}-w_{r}, w_{e}, \tau_{i}\right)=\operatorname{Max}\left(p_{r}-w_{r}-c_{r h}\left(w_{e}\right)-e_{r h}\left(w_{e}\right) \tau_{i} ; 0\right)$.

(8) $\pi^{i h}\left(p_{i}-w_{i}, w_{e}, \tau_{r}\right)=\operatorname{Max}\left(p_{i}-w_{i}-c_{i h}\left(w_{e}\right)-e_{i h}\left(w_{e}\right) \tau_{r} ; 0\right)$.

\footnotetext{
${ }^{5}$ This externality cost arises because of the cost of dedicating some equipment to regular rapeseed and some to IP rapeseed (see section 2).
} 
Because of the linearity of the profit functions, it is always optimal for a handler to handle only one crop, the one that yields the maximum profit level. Therefore we have (omitting argument $w_{e}$ ):

(9) $\pi^{\operatorname{maxh}}\left(p_{i}-w_{i}, p_{r}-w_{r}, \tau_{i}\right)=\operatorname{Max}\left(\pi^{r h}\left(p_{r}-w_{r}, \tau_{i}\right) ; \pi^{i h}\left(p_{l}-w_{i}, 1-\tau_{i}\right)\right)$.

We assume that costs $c_{r h}\left(w_{e}\right)$ and $c_{i h}\left(w_{e}\right)$ vary among handlers (some handlers have technological advantages in handling regular or IP rapeseed because different grain elevators are configured differently). In equilibrium, some handlers may find it most profitable to handle regular rapeseed, while others may find it most profitable to handle IP rapeseed. Handler $h$ 's supply function for handled crop (for $k \in\{i, r\}$ ) is then identical to handler $h$ 's demand function for farm crop $k$ and defined by:

$$
q_{k}^{\text {sdh }}\left(p_{r}-w_{r}, p_{i}-w_{i}, \tau_{i}\right)= \begin{cases}Q & \text { if } \pi^{\operatorname{maxh}}(.)=\pi^{k h}(.) \\ 0 & \text { otherwise }\end{cases}
$$

The aggregate handler supply function of crop $k$, which is identical to the aggregate handler demand function of crop $k, k \in\{i, r\}$, is denoted $q_{k}^{s d A H}($.$) , and is$ defined as the sum of individual handler supply functions:

(11) $q_{k}^{s d A H}\left(p_{r}-w_{r}, p_{i}-w_{i}, \tau_{i}\right)=\sum_{h=1}^{H} q_{k}^{s d h}\left(p_{r}-w_{r}, p_{i}-w_{i}, \tau_{i}\right)$

\section{Domestic final consumers}

We consider a set of $C$ consumers, and we assume that the utility of consumer $c$ $\in\{1, \ldots, C\}$ takes the form:

(12) $U^{c}\left(q_{r}, q_{i}, q_{b}, q_{z}\right)=\left\{\begin{array}{l}a K+q_{z} \text { if } \sigma_{r c} q_{r}+q_{i}+\sigma_{b c} q_{b} \geq K \\ a\left(\sigma_{r c} q_{r}+q_{i}+\sigma_{b c} q_{b}\right)+q_{z} \text { otherwise }\end{array}\right.$, 
where $r$ is regular rapeseed, $i$ is IP rapeseed, $b$ is a close substitute with rapeseed in consumption, $z$ is a numeraire good, $q_{j}$ denotes the quantity of good $j$, and $\sigma_{r c}, \sigma_{b c}$, $a$ and $K$ are constant positive parameters.

We assume that for $c=1, \ldots, C, \sigma_{b c}>0$ and $0 \leq \sigma_{r c} \leq 1$ : each consumer may reach subutility $u$ from consuming the substitute good, but some consumers have no utility from consuming regular rapeseed; and to get the subutility $u$ from consuming rapeseed only, it is always necessary to consume at least as much regular rapeseed as IP rapeseed (but for some consumers these quantities may be equal). Consumer c's Marshallian demand functions for goods $r, i$, and $b$ and indirect utility function are given by: ${ }^{6}$

(13) $q_{r c}^{d}\left(p_{r}, p_{i}, p_{b}\right)=\left\{\begin{array}{l}\frac{K}{\sigma_{r c}} \text { if } p_{r}<p_{i} \sigma_{r c} \text { and } p_{r} \sigma_{b c} \leq p_{b} \sigma_{r c} \\ 0 \quad \text { otherwise }\end{array}\right.$,

(14) $q_{i c}^{d}\left(p_{r}, p_{i}, p_{b}\right)=\left\{\begin{array}{ll}K & \text { if } p_{i} \sigma_{r c} \leq p_{r} \text { and } p_{i} \sigma_{b c} \leq p_{b} \\ 0 & \text { otherwise }\end{array}\right.$,

(15) $q_{b c}^{d}\left(p_{r}, p_{i}, p_{b}\right)= \begin{cases}\frac{K}{\sigma_{b c}} & \text { if } p_{b} \sigma_{r c}<p_{r} \sigma_{b c} \text { and } p_{b}<p_{l} \sigma_{b c} \\ 0 & \text { otherwise }\end{cases}$

(16) $V^{c}\left(p_{r}, p_{i}, p_{b}, M\right)=M+a K-K \operatorname{Min}\left(\frac{p_{r}}{\sigma_{r c}}, p_{i}, \frac{p_{b}}{\sigma_{b c}}\right)$.

The money metric indirect utility function of consumer $c$ is given by:

(17) $\mu^{c}\left(\bar{p}^{1}, \bar{p}^{0}, M\right)=V^{c}\left(\bar{p}^{1}, M\right)-V^{c}\left(\bar{p}^{0}, M\right)$,

where $\bar{p}^{s}=\left(p_{r}^{s}, p_{l}^{s}, p_{b}^{s}\right)$ is a vector of prices in situation $s$.

${ }^{6}$ We arbitrarily decide that each consumer consumes only one of the goods $r, i$ and $b$ when he is indifferent between two or three of these goods, with good $i$ being the most preferred, then $r$, then $b$. 
Each consumer consumes only one of goods $b, r$, or $i$. We consider a set of $C$ consumers with different values for parameters $\sigma_{r c}$ and $\sigma_{b c}$, and, so that in equilibrium some may consume regular handled rapeseed, some may consume nonGM, IP handled rapeseed and some may consume the substitute good. Consumers' aggregate demand function for good $k \in\{r, i, b\}$ is denoted $q_{k}^{d A C}($.$) and is defined as$ the sum of individual demands for that good:

$$
q_{k}^{d A C}\left(p_{r}, p_{i}\right)=\sum_{c=1}^{c} q_{k}^{d c}\left(p_{r}, p_{i}\right), k \in\{r, i, b\}
$$

\section{Excess demand from the rest of the world and equilibrium conditions}

We assume that consumers in the rest of the world are indifferent between regular and IP rapeseed. Because the consumer price of IP rapeseed, $p_{i}$, is necessarily higher than the consumer price of regular rapeseed, $p_{r}$, in our model, consumers in the rest of the world consume only regular rapeseed. The excess demand of regular rapeseed in the rest of the world is denoted by $q_{r}^{d M}\left(p_{r}\right)$. Equilibrium conditions in our model are as follows:

(23) $\tau_{i}=\frac{q_{i}^{s d A H}\left(p_{r}-w_{r}, p_{i}-w_{i}, \tau_{i}\right)}{q_{r}^{s d A H}\left(p_{r}-w_{r}, p_{i}-w_{i}, \tau_{i}\right)+q_{i}^{s d A H}\left(p_{r}-w_{r}, p_{i}-w_{i}, \tau_{i}\right)}$

Equation (19) states that in equilibrium, the quantity of GM rapeseed plus the quantity of non-GM, non-IP rapeseed supplied by domestic farmers is equal to the 
quantity of regular rapeseed demanded and supplied by domestic handlers. Equation (20) states that in equilibrium, the quantity of $\mathbb{P}$ rapeseed supplied by domestic farmers is equal to the quantity demanded and supplied by domestic handlers. Equation (21) states that in equilibrium, the quantity of regular rapeseed supplied by domestic handlers is equal to the quantity demanded by domestic consumers plus the excess quantity demanded by the rest of the world. Equation (22) states that in equilibrium, the quantity of IP rapeseed supplied by domestic handlers is equal to the quantity demanded by domestic consumers. Equation (23) states that in equilibrium, the value of $\tau_{i}$ is equal to the quantity of IP rapeseed supplied by domestic handlers divided by the total quantity of rapeseed handled by domestic handlers. The five equations (19) - (23) may be solved for four equilibrium prices, $\left(w_{r}, w_{i}, p_{r}, p_{i}\right)$ and the equilibrium share of IP crops in the handling system, $\tau_{i}$.

\section{Calibration of the model}

We develop a simulation model to illustrate empirically our modeling framework in the case of rapeseed in the EU and the rest of the world. This model is developed using realistic assumptions on parameter values, presented in this section. Simulation results are presented in section 6 . The simulation model represents the rapeseed market in the EU and the rest of the world in 1999/2000. In the simulation model, quantities are in metric tons (denoted by $\mathrm{t}$ ), areas are in hectares (denoted by ha), and prices are in euros. In the baseline situation, only non-GM non-IP rapeseed, i.e., rapeseed $n$, is produced by EU farmers, and due to regulations GM rapeseed cannot be produced or imported in the EU. In the baseline situation this farm rapeseed $n$ is processed by handlers into regular handled rapeseed, i.e., rapeseed $r$, which is 
either consumed domestically or exported to the rest of the world. Consumers in the EU are indifferent between regular and IP rapeseed. ${ }^{7}$

Baseline EU farm and handled rapeseed production $\left(q_{n 0}^{s A F}=q_{r 0}^{s d A H}\right)$ is equal to 11.55 million tons, out of which 10.55 million tons are consumed domestically and 1 million ton is exported to the rest of the world. The rest of the world produces 31 million tons of rapeseed and consumes 32 million tons. The EU farm rapeseed price is 152 euros/t, and the EU handled rapeseed price is 183 euros/t. The EU subsidy on rapeseed is 564 euros/ha. ${ }^{8}$ The price of the close substitute to rapeseed in consumption is $p_{b}=183$ euros/t. In our model we assume the numbers of types of domestic farmers, handlers and consumers to be $F=2000 ; H=1500 ; C=2000 .^{9}$ In the baseline situation, 1000 farmers grow rapeseed while 1000 farmers grow the alternative crop $a ; 1000$ handlers handle rapeseed and 500 handlers do not handle rapeseed; 1000 consumers consume rapeseed while 1000 consumers consume its close substitute $b$. Land on each farm is $L=3,500$ ha; storage capacity per handler is $Q=11,550 \mathrm{t}$; parameter of the utility function is $K=10,550 \mathrm{t}$. EU rapeseed yield is $3.3 \mathrm{t} / \mathrm{ha}$. In the baseline situation,

${ }^{7}$ In our simulation model, the EU is a net exporter of rapeseed. As a result, in the initial situation, even consumers who refuse to consume GMOs are not worse off from consuming non IP rapeseed, given that all rapeseed they consume is produced in the EU, and is non-GM in the initial situation. In reality, we can think of two reasons why some consumers would want to consume only IP rapeseed even if no GMOs were produced in the EU: 1) Consumers could be uninformed about the origin of the rapeseed they consume, or worried about consuming rapeseed that could have been cross-pollinated by GM rapeseed from a trial field. 2) The EU is a net exporter of rapeseed and rape oil, but is a net importer of rape meal. Imported rape meal is mainly used for livestock feed. Therefore, some consumers may prefer IP to assure themselves about not having eaten meat from an animal fed with GMOs.

${ }^{8}$ EU rapeseed area, yield, production and exports from Oil World Statistics Update, year 1999/2000, March 30, 2001. A rapeseed net export equivalent was calculated using a price-weighted average of EU net exports of rapeseed, net exports of rape oil and a net imports of rape meal. Per hectare rapeseed subsidy from les cahiers de l'ONIC, modèle MONIC: marchés céréaliers: perspectives européennes à l'horizon 2005, October 2000, ONIC, France. Farm production price from Agreste, Agreste conjoncture, le bulletin, $\mathrm{n}^{\circ} 5$, May 2001, Ministère de 1'Agriculture et de la Pêche, France. Handled export price from CETIOM, Colza d'hiver: les techniques culturales, le contexte économique, May 2000, France.

9 We refer to them later simply as "farmers", "handlers" and "consumers", but they are rather types of farmers, handlers and consumers. 
price elasticities of farm rapeseed supply in the EU and handled rapeseed supply in the ROW are equal to 0.5 . Price elasticities of handled rapeseed demand in the EU and in the ROW are equal to -0.5 .

\section{Parameters for farmers}

We index farms in the order of their per-hectare variable cost of production for crop $n$; i.e., $c_{n 1}<\ldots<c_{n 2000}$. To calibrate values $c_{n 1}, \ldots, c_{n 2000}$ and $\pi_{a}$, we consider the case where only non-GM non-IP rapeseed and the alternative crop are grown $\left(\tau_{i}=0\right)$. We use $f^{\prime}$ to denote the index number of the farm with the highest per-hectare variable cost of production for crop $n\left(c_{n f^{\circ}}\right)$ among all farmers growing crop $n$ in equilibrium. We then rely on two assumptions. First, we assume that the aggregate farm supply function for crop $n$ takes on the constant elasticity form $q_{n}^{s A F}=\alpha w_{r}^{0.5}$, when the marginal farm $f^{\prime}$ is indifferent between producing crop $n$ or crop $a .^{10}$ Second, we assume that the average revenue of the 1000 farmers who grow rapeseed $n$ in the baseline situation, including the subsidy, is equal to twice their average cost $c_{n f} \cdot{ }^{11} \mathrm{We}$ use these two assumptions in the appendix to show that in our model $\pi^{a}$ and $c_{n f}$ are defined by: $\pi^{a}=198.7$ and $c_{n f}=501.6 \times 10^{-6} \times f^{2}+564-\pi^{a}$, for $f=1, \ldots, 2000$.

Values $c_{g 1}, \ldots, c_{g^{2000}}$ are calibrated using results of Desquilbet, Lemarié and Levert (2001), who estimate potential adoption of GM rapeseed using data on nonGMO herbicide costs from French rapeseed farmers. In a simulation where the GMO

\footnotetext{
${ }^{10}$ The assumption of constant elasticity supply and demand curves is common in models with researchinduced supply shifts. The most common alternative is linear supply and demand curves. In our case, some farmers have negative production costs with a linear supply curve, because the elasticity of supply is less than 1 in the baseline situation. We prefer the constant elasticity assumption, which implies that production costs are necessarily positive (see Alston, Norton and Pardey, p. 61).
} 
supplier sets the GM seed price at its profit-maximizing level, with other input prices kept constant, they estimate a mean farm herbicide cost reduction of 64.6 euros/ha. They estimate an empirical standard deviation of 30.2 , with $71 \%$ of farmers adopting GMOs. In our model; we implicitly define per-hectare GMO cost reductions $r_{1}, \ldots, r_{2000}$ by the equation $\Phi\left(r_{f}\right)=f / 2000$, for $f=1, \ldots, 2000$, where $\Phi(r)$ is the normal cumulative distribution function of a random variable $r$ of mean 64.6 and standard deviation 30.2. To avoid correlation between GMO cost reductions and production costs for rapeseed $n$, we take a random permutation $\left\{r_{1}{ }^{\prime}, \ldots, r_{2000}{ }^{\prime}\right\}$ of the list $\left\{r_{1}, \ldots, r_{2000}\right\}$. We then define $c_{g j}$ as $c_{n j}$ minus the GMO cost reduction, $r_{j}{ }^{\prime}$, plus the license cost of the GM seed, denoted $l c$. That is, $c_{g f}=c_{n f}-r_{f}{ }^{\prime}+l c$, $f=1, \ldots, 2000$. In the baseline situation, we set the license cost to 1000 euros/ha, which is high enough to cause no farmer to grow GMOs. In the simulation, in which GMOs are adopted in the EU, we set the license cost to 48 euros/ha. (We checked that this value results in a $71 \%$ adoption rate of GMOs by farmers growing rapeseed, in a situation where no consumer refuses GMOs). With these assumptions, GM technology is cost-saving for some farmers, but not all farmers (we may have $c_{n f}>c_{g f}$ or $c_{n f} \leq c_{g f}$ depending on the farm).

For a given farmer $f$, the value $c_{i f}-c_{n f}$ represents the difference between the per-hectare production costs of IP rapeseed and non-GM non-IP rapeseed, excluding the externality cost. We expect that farmers have positive costs of identity preservation, but that these costs are very small in a situation when only IP crops are

\footnotetext{
${ }^{11}$ This assumption is consistent with Agreste, 2001.
} 
grown, i.e. we expect the above cost difference to be very small. ${ }^{12}$ We arbitrarily set: $c_{i f}=c_{n f}+0.1$ euros/ha, $f=1, \ldots, 2000$.

We can expect the average farm externality parameter for IP rapeseed to be higher than the average farm externality parameter for non-GM non-IP or GM rapeseed. For the externality parameters for $\mathrm{IP}$ rapeseed include the potential higher cost of buying a non-GM IP seed (which costs more because seed production companies must also prevent cross-pollination) and of preventing cross-pollination, while no equivalent costs exist for regular rapeseed. Moreover, we can expect the potential additional cost to bring IP rapeseed to an elevator accepting it to be higher than the equivalent cost for regular rapeseed. (Because handling IP rapeseed is more difficult than handling regular rapeseed, it can be expected that in average farmers would face higher restrictions about where to deliver $\mathbb{P}$ than they would face for regular rapeseed). Moreover, these externality costs are expected to vary between farmers. Given these expectations, we arbitrarily define $\left\{e_{r 1}, \ldots, e_{r 2000}\right\}$ by a random permutation of the list composed of 2000 ordered equidistant points between 0 and 20 euros/ha, and we arbitrarily define $\left\{e_{i 1}, \ldots, e_{i 2000}\right\}$ by a random permutation of the list composed of 2000 ordered equidistant points between 0 and 40 euros/ha.

\section{Handling productions costs}

Parameters $c_{r h}$ (the cost of handling regular rapeseed, excluding the cost of farm rapeseed and the handler's externality cost) are calibrated in an analogous manner to parameters $c_{n f}:$ in the case where no IP rapeseed is supplied $\left(\tau_{i}=0\right)$, we

\footnotetext{
${ }^{12}$ For example, in the current situation in France, only non-GM corn is grown, although some varieties of GM corn are authorized. To deliver IP corn, the only costly action for a farmer is to sign a contract with the elevator certifying that no GM seed was used.
} 
assume that the relation $q_{r}^{s d A H}=\beta\left(p_{r}-w_{r}\right)^{0.5}$ is verified when the handler with the highest cost $c_{r h}$ among handlers handling regular rapeseed is indifferent between handling regular rapeseed or handling nothing. We then find: $c_{r h}=31 \times 10^{-6} \times h^{2}$.

We expect the cost difference $c_{i h}-c_{r h}$ to be positive for each handler. That is, we expect that for each handler, the cost of handling $\mathbb{P}$ rapeseed in a situation in which $\mathbb{P}$ rapeseed strongly predominates in the handling system would be higher than cost of handling regular rapeseed in a situation in which regular rapeseed predominates. The additional cost would be derived from writing and enforcing contracts along the supply chain, and from using chemical tests to prove the absence of GMOs. We also expect these costs to vary depending on handlers (depending on the complexity of handling operations). ${ }^{13}$ We generate a set of parameters $c_{i p h}$ by taking 1500 equidistant points between 2 and 4 euros/t. We take a random permutation $\left\{c_{l p h 1}{ }^{\prime}, \ldots, c_{i p h 1500}{ }^{\prime}\right\}$ of the list $\left\{c_{i p h 1}, \ldots, c_{l p h 1500}\right\}$. We then define: $c_{i h}=c_{r h}+c_{i p h}{ }^{\prime}, h=1, \ldots, 1500$.

We can expect the average handling externality parameter for IP rapeseed to be higher than the average handling externality parameter for regular rapeseed. As a matter of fact, when both regular and $\mathbb{P}$ rapeseed are present in the handling system, the costs of cleaning equipment are expected to be higher in average for IP rapeseed (for which any GMO commingling should be avoided) and the costs of dedicating equipment to $\mathbb{P}$ rapeseed are expected to be higher in average than the costs of dedicating equipment to regular rapeseed (for example, having a common dump pit in

13 Testing costs depend on the number of different GMOs that must be identified and on the available tests. For example, Bullock and Desquilbet (2001) estimate that in the current situation in the US a typical testing cost is $0.87 \$ / t$ for soybeans and $3.31 \$ / t$ for corn. With an exchange rate of 1.12 euros for $1 \$$, these costs correspond to 0.97 and 3.7 euros/t, respectively. 
an elevator makes it more difficult to dedicate equipment to IP rather than regular rapeseed). Moreover, these externality costs are expected to vary between handlers. Given these expectations, we arbitrarily define handling externality parameters $\left\{e_{r 1}, \ldots, e_{r 1500}\right\}$ by a random permutation of the list composed of 1500 ordered equidistant points between 0 and 20 euros/ha, and we arbitrarily define $\left\{e_{i 1}, \ldots, e_{i 1500}\right\}$ by a random permutation of the list composed of 1500 ordered equidistant points between 0 and 40 euros/ha.

\section{Domestic demand parameters}

In the baseline simulation, only regular rapeseed and the substitute good are consumed and all consumers are indifferent between regular and IP rapeseed, i.e. all parameters $\sigma_{r c}$ are equal to 1 . Consumers are indexed such that $\sigma_{b 1}<\ldots<\sigma_{b 2000}$. To calibrate values $\sigma_{b 1}, \ldots, \sigma_{b 2000}$, we assume that the constant elasticity form $q_{r}^{d A C}=\gamma p_{r}^{-0.5}$ is verified when the consumer with the lowest preference for good $r$ among those consuming good $r$ is exactly indifferent between consumption of good $r$ or good $b$. We then obtain: $\sigma_{b c}=10^{-6} \times c^{2}$, for $c=1, \ldots, 2000$. In the simulation, we assume that one consumer out of two refuses non IP rapeseed. In this case, $\sigma_{r c}$ is set equal to zero for even values of $c$, and to 1 for odd values of $c$.

\section{Rest of the world}

We take constant elasticity supply and demand curves for handled regular rapeseed in the rest of the world. The supply elasticity is 0.5 and the demand elasticity is -0.5 in the baseline situation. We take production and consumption levels in the rest of the world respectively equal to 31 million $t$ and 32 million $t$ in the baseline 
situation (Oil World Statistics Update, year 1999/2000, March 30, 2001, and Table 1). We obtain ROW domestic supply and demand curves defined by $q^{\text {sROW }}=183^{-0.5} \times 31 \times 10^{6} p_{r}^{0.5}$ and $q^{\text {dROW }}=183^{0.5} \times 32 \times 10^{6} p_{r}^{-0.5}$. The import demand curve is then defined by: $q_{M}^{d}=q^{d R O W}-q^{\text {sROW }}$.

\section{Simulation}

We present the results of a simulation analyzing the consequences of the simultaneous introduction of GM rapeseed technology, a shift in half of the consumers' preferences in favor of non-GM IP rapeseed (good $i$ ), and the introduction of segregation and identity preservation in the EU.

\section{Equilibrium prices and quantities}

Compared with the baseline situation, the equilibrium price of farm regular rapeseed decreases by about $3 \%$ to 147.5 euros/t from 152 euros/t. The equilibrium price of handled regular rapeseed decreases by about $0.8 \%$ to 181.6 euros/t from 183 euros/t. The equilibrium price of farm IP rapeseed is higher than the price of farm rapeseed at the baseline, at 153.4 euros/t. The equilibrium price of handled $\mathrm{P}$ rapeseed is equal to 195.6 euros/t. There is a 42.2 euros/t wedge between the price of farm IP rapeseed and handled IP rapeseed, and 34.1 euros/t wedge between the price of farm regular rapeseed and handled regular rapeseed. These wedges are higher than the 31 euros/t wedge between farm-gate and handler prices in the baseline scenario, and reflect higher costs due to identity preservation.

In the regular rapeseed market, EU farm and handled supply is equal to 6.52 million tons. More than $99 \%$ of farm regular rapeseed is GM rapeseed. EU domestic consumption is equal to 5.28 million tons, and exports to the rest of the world are 
equal to 1.24 million tons. In the IP rapeseed market, EU farm and handlers' production and EU domestic consumption are equal to 5.10 million tons.

\section{Who wins and who loses}

Here we compare profits and utilities in the baseline situation to the nonbaseline situation. Total profits of farmers decrease by 30 million euros, total profits of handlers decrease by 12 million euros and total utility of domestic consumers decreases by 58 million euros (Table 1). In total, domestic welfare decreases by 100 million euros.

Tables 2 to 4 show the change in profits and utilities for different groups of domestic farmers, handlers and final consumers. Consumers who refuse to consume GMOs lose from the introduction of GM technology, even though IP products are available, because the price they have to pay for IP rapeseed is higher than the price they paid for regular rapeseed (that was all non-GMO) in the baseline situation. These consumers, however, do not bear alone all the costs of IP. Profits of farmers who keep producing non-GM non-IP rapeseed decrease. Profits of farmers who turn from nonGM non-IP rapeseed to IP rapeseed or to the alternative crop decrease as well. Profits of handlers who keep handling regular rapeseed or who stop handling rapeseed decrease too.

Even though identity preservation creates externality costs for regular rapeseed, farmers with a high cost advantage in GM rapeseed relative to non-GM rapeseed win from the introduction of GM technology. And consumers who sense no difference between GMOs and non-GMOs win, because they face a lower price than in the baseline situation (although this price may have been even lower in the absence of 
externality costs due to the existence of the IP rapeseed supply channel). ${ }^{14}$ Finally, handlers efficient at handling $\mathbb{P}$ rapeseed win.

\section{Conclusions}

The situation of GMO and non-GMO market segregation raises a range of positive as well as normative questions: who pays the costs in the absence of intervention; who should pay the costs; what kind of government intervention can increase global welfare. In this paper, we propose a framework specifying supply and demand functions at the individual level to study the first question. This framework allows us to circumvent the difficulties of conducting supply and demand analysis in the different horizontally and vertically related markets concerned by GMOs and market segregation. In addition, because our framework is built on individual heterogenous agents, it allows us to quantify welfare effects for farmers, handlers or consumers in general, but also welfare effects depending on various characteristics that describe the various agents.

Our simulation results are still preliminary given the lack of data on costs of GMO segregation and identity preservation. But they point in several interesting directions and suggest further research. First, it would be important to conduct sensitivity analysis on some key parameters of the model, notably parameters describing the costs of $I P$, and parameters describing the preferences of consumers towards GMO and non-GMO products. Second, this framework could be extended to analyze the welfare effects of public policy instruments, such as a taxation of GMO producers or a subsidy to non-GMO producers.

\footnotetext{
${ }^{14}$ Our analysis strictly considers economic effects. We do not consider the possibility that GMOs might actually have harmful health effects on consumers or harmful environmental effects.
} 


\section{References}

Agreste (2001), Chiffres et Données, Agriculture, $n^{\circ}$ 131, February 2001, Rica France: Tableaux Standard 1999, Ministère de l'Agriculture et de la Pêche, France.

Alston J.M., Norton G.W., Pardey P.G. (1998). Science under Scarcity: Principles and Practice for Agricultural Research Evaluation and Priority Setting. CAB International, Oxon, UK, New York, USA.

Bullock, D.S., Desquilbet, M. (2001). The economics of non-GMO segregation and identity preservation. Working document, October 23.

Bullock, D. S., Nitsi., E. I. Roundup Ready Soybean Technology and Farm Production Costs: Measuring the Incentive to Adopt. American Behavioral Scientist 44(April 2001), 1283-1301.

Desquilbet, M., Lemarié, S., Levert, F. (2001). Potential adoption of GM crops in France, effects on revenues of farmers and upstream companies: an ex ante evaluation, $5^{\text {th }}$ ICABR conference "Biotechnology, science and modern agriculture: a new industry at the dawn of the century", Ravello, Italy, June 1518,2001 .

Giannakas, K., Fulton, M. (2001). Consumption effects of genetic modification: what if consumers are right?. Forthcoming in Agricultural Economics.

Golan, E., Kuchler, F. (2000). Labeling biotech foods: implications for consumer welfare and trade. Presented at International Agricultural Trade Research Consortium Symposium, Montreal, Canada, June 26-27.

Mayer, H., Furtan, W.H. (1999). Economics of transgenic herbicide-tolerant canola: The case of Western Canada. Food Policy 24: 431-442. 
McBride, W.D. and Books, N. (2000). Survey Evidence on Producer Use and Costs of Genetically Modified Seed. In Transitions in Agbiotech: Economics of Strategy and Policy. Lesser, W.E. (ed). Proceedings of the NE-165 Conference, June 2425 1999, Washington, D.C., 2000, University of Connecticut and University of Massachussetts, pp 22-40.

Nielsen, C. P., Thierfelder, K., Robinson, S. (2001). Consumer Attitudes Towards Genetically Modified Foods: The Modelling of Preference Changes. Paper prepared for the 5th International Conference on "Biotechnology, Science and Modern Agriculture: a New Industry at the Dawn of the Century", Ravello, Italy, June 2001. 


\section{Appendix: calibration of the model}

- Farm production costs of rapeseed $n$ and profit on the alternative crop: We calibrate our model considering the case in which no non-GM IP rapeseed is grown $\left(\tau_{i}=0\right)$, and therefore where there is no externality cost for farmers growing regular rapeseed. When farm. $f=1, \ldots, 2000$ grows rapeseed $n$, its per-hectare profit is $\pi^{n f}=w_{r} y+s-c_{n f}$ and its total production is $q_{n}^{s}=y L$. From the baseline production and price values, $\alpha=(152)^{-0.5} \times 11.55 \times 10^{6}$. In an equilibrium where farms 1 to $f^{\prime}$ produce good $n$, profits the marginal farm $f^{\prime}$ of growing crop $n$ will equal its profits from growing the alternative crop, so $\pi^{n f^{\prime}}=w_{r} y+s-c_{n f^{\prime}}=\pi^{a}$. Therefore in equilibrium, $w_{r}=\frac{\pi^{a}-s+c_{n f^{\prime}}}{y}$. Since aggregate production is $q_{n}^{s A F}=f y L$ then assuming the aggregate supply function takes on the constant elasticity functional form implies $q_{n}^{s A F}=\alpha\left(w_{r}\right)^{0.5}$; that is, $f^{\prime} y L=\alpha\left(\frac{\pi^{a}-s+c_{n f^{\prime}}}{y}\right)^{0.5}$, or, equivalently, $\pi^{a}+c_{n f^{\prime}}=y\left(\frac{f^{\prime} y L}{\alpha}\right)^{2}+s$. Using values of parameters $\alpha, L, s$ and $y$, this defines: $\pi^{a}+c_{n f^{\prime}}=501.6 \times 10^{-6} \times f^{\prime 2}+564$. The constant elasticity functional form of aggregate supply function implies:

(A1) $c_{n f}=501.6 \times 10^{-6} \times f^{2}+564-\pi^{a}$ for $f=1, \ldots, 2000$

Per hectare revenue on rapeseed $n$ in baseline situation is: $w_{r} y+s=152 \times 3.3+564=1065.6$ euros $/$ ha. Then, under the assumption that per hectare revenue is twice the mean of the per hectare costs of the 1000 farmers who grow crop in in the baseline equilibrium, we have: 
(A2) $\frac{1}{1000} \sum_{f=1}^{1000} c_{n f}=1065.6 / 2=532.8$ euros $/$ ha.

From the equations (A1) and (A2), we can solve for $\pi^{a}$ and $c_{n f}, f=1, \ldots, 2000$.

- Handling costs of rapeseed r: From baseline production and price values, we have: $\beta=31^{-0.5} \times 11.55 \times 10^{6}$. The constant elasticity form can also be written $h Q=\beta c_{r h}{ }^{0.5}$, or equivalently: $c_{r h}=\left(\frac{h Q}{\beta}\right)^{2}=31 \times 10^{-6} \times h^{2}$.

- Domestic demand parameters: From production and price baseline values, $\gamma=$ $(183)^{0.5} \times 10.55 \times 10^{6}$. When consumers 1 to $c$ consume good $r$, the aggregate production is $q_{r}^{d A C}=c K$, and the constant elasticity form is verified for $\sigma_{b c}=p_{b} / p_{r}$. It can then be written: $c K=\gamma\left(\frac{p_{b}}{\sigma_{b c}}\right)^{-0.5}$, or, equivalently, $\sigma_{b c}=p_{b}\left(\frac{\gamma}{c K}\right)^{-2}$. Using values of parameters $\gamma, p_{b}$ and $K$, this defines: $\sigma_{b c}=10^{-6} \times c^{2}$, for $c=1, \ldots, 2000$. 
Table 1. Prices, quantities, profits and utilities in the baseline situation and in the simulation

\begin{tabular}{|c|c|c|}
\hline & baseline situation & simulation 1 \\
\hline \multicolumn{3}{|l|}{ prices (euros/t) } \\
\hline$w_{r}$ & 152 & 147.5 \\
\hline$p_{r}$ & 183 & 181.6 \\
\hline$w_{i}$ & n.a. & 153.4 \\
\hline$p_{i}$ & n.a. & 195.6 \\
\hline \multicolumn{3}{|l|}{ quantities (million t) } \\
\hline$q_{n}^{s A F}$ & 11.55 & 0.05 \\
\hline$q_{g}^{s A F}$ & 0 & 6.47 \\
\hline$q_{r}^{s d A H}$ & 11.55 & 6.52 \\
\hline$q_{r}^{d A H}$ & 10.55 & 5.28 \\
\hline$q_{r}^{d M}$ & 1.0 & 1.24 \\
\hline$q_{i}^{s A F}=q_{i}^{s d A H}=q_{i}^{d A H}$ & 0 & 5.10 \\
\hline \multicolumn{3}{|l|}{$\begin{array}{c}\text { profits and utilities (million } \\
\text { euros) }\end{array}$} \\
\hline domestic farmers' profit & 2618 & 2588 \\
\hline domestic handlers' profit & 262 & 250 \\
\hline domestic consumers' utility & $2000(M+10550)-2895$ & $2000(M+10550)-2953$ \\
\hline domestic total welfare & $2000(M+10550)-15$ & $2000(\mathrm{M}+10550)-115$ \\
\hline
\end{tabular}


Table 2. Change in profits of farmers' groups (baseline situation to simulation)

\begin{tabular}{|c|c|c|}
\hline Domestic farmers' group & number of farmers & $\begin{array}{c}\text { average change in } \\
\text { profit per ton (euros) }\end{array}$ \\
\hline rapeseed $n \rightarrow$ rapeseed $n$ & 5 & -4.96 \\
\hline rapeseed $n \rightarrow \operatorname{crop} a$ & 5 & -2.78 \\
\hline rapeseed $n \rightarrow$ rapeseed $i$ & 440 & -1.62 \\
\hline crop $a \rightarrow$ crop $a$ & 988 & 0 \\
\hline rapeseed $n \rightarrow$ rapeseed $g$ & 549 & +5.68 \\
\hline crop $a \rightarrow$ rapeseed $g$ & 13 & +5.89 \\
\hline
\end{tabular}

Note: This Table assumes that the yield on the alternative crop is equal to the yield on rapeseed. Column 1 defines the farmers belonging to the group. For example, "rapeseed $n \rightarrow$ rapeseed $g$ " is the farmers growing crop $n$ in the baseline situation and crop $g$ in the simulation. Column 2 indicates the number of farmers to whom the change described in column 1 applies. Column 3 indicates the average change in profit for this group from the baseline situation to the simulation. 
Table 3. Change in profits of handlers' groups (baseline situation to simulation)

\begin{tabular}{|c|c|c|}
\hline Domestic handlers & number of handlers & $\begin{array}{c}\text { average change in } \\
\text { profit per ton (euros) }\end{array}$ \\
\hline rapeseed $r \rightarrow$ no rapeseed & 18 & -1.36 \\
\hline rapeseed $r \rightarrow$ rapeseed $r$ & 558 & -0.78 \\
\hline no rapeseed $\rightarrow$ rapeseed $r$ & 5 & +0.76 \\
\hline no rapeseed $\rightarrow$ rapeseed $i$ & 20 & +3.13 \\
\hline rapeseed $r \rightarrow$ rapeseed $i$ & 424 & +3.28 \\
\hline no rapeseed $\rightarrow$ no rapeseed & 475 & 0 \\
\hline
\end{tabular}


Table 4. Change in money metric utility of domestic final consumers' groups (baseline situation to simulation)

\begin{tabular}{|c|c|c|}
\hline Domestic final consumers & number of & $\begin{array}{c}\text { average change in } \\
\text { money metric utility (in } \\
\text { equivalent per ton of } \\
\text { rapeseed } i \text { ) (euros) }\end{array}$ \\
\hline rapeseed $r \rightarrow$ rapeseed $i$ & 484 & -12.6 \\
\hline rapeseed $r \rightarrow \operatorname{good} b$ & 16 & -6.0 \\
\hline good $b \rightarrow \operatorname{good} b$ & 999 & 0 \\
\hline good $b \rightarrow \operatorname{rapeseed} r$ & 1 & +0.66 \\
\hline rapeseed $r \rightarrow \operatorname{rapeseed} r$ & 500 & +1.39 \\
\hline
\end{tabular}

Note: The average change in money metric utility in equivalent per ton of rapeseed $i$ is obtained by dividing the average change in money metric utility per consumer by the parameter $\mathrm{K}$ of the utility function (this parameter gives the quantity of rapeseed $i$ that each consumer would consume if he chose to consume rapeseed $i$ ). 
